\title{
Correction to: Ontological commitments of frame-based knowledge representations
}

\author{
David Hommen ${ }^{1}$ (D)
}

Published online: 2 April 2018

(C) Springer Science+Business Media B.V., part of Springer Nature 2018

\section{Correction to: Synthese https://doi.org/10.1007/s11229-017-1649-8}

In Hommen (2017), I refer to the work of Garcia in Garcia (2015a, b). In this addendum, I would like to supplement additional references to these papers.

In the second paragraph of Section 2.2 of Hommen (2017, pp. 6-7), I describe the doctrine of property realism with reference to Garcia (2015a, p. 141). The last sentence of that paragraph on page 7 should repeat that reference without "cf."

The first sentence of the last paragraph of Section 2.2 (p. 7) should contain a reference to Garcia (2015a, p. 108).

In Section 4.1 (p. 12), I attribute the Principle of Absolute Determinateness to Campbell (1990, pp. 83-84). However, the qualification "under that determinable" is not present in the formulation of the Principle that Campbell advances. This qualification is found in Armstrong (1997, p. 48), Gillet and Rives (2005, p. 485) and Funkhouser (2006, p. 549) — which are cited in that context-as well as in Garcia (2015a, p. 151).

In the first paragraph of Section 5.1 (pp. 15-16), the "cf." in the reference to Garcia (2015a, p. 142) should be removed.

In the third paragraph of Section 5.1 (p. 16), I describe the distinction between objects and properties in terms of the notion of (nonmereological) inherence. The idea

The original article can be found online at https://doi.org/10.1007/s11229-017-1649-8.

David Hommen

hommen@hhu.de

https://www.uni-duesseldorf.de;

https://www.phil-fak.uni-duesseldorf.de/philo/personal/thphil/dr-david-hommen/

1 Heinrich-Heine-Universität Düsseldorf, Universitätsstraße 1, 40204 Düsseldorf, Germany 
that the object/property distinction "opens a categorial gap" is discussed in Garcia (2015a, pp. 138-144).

In the first paragraphs of Section 5.2 (p. 17) and Section 5.3 (p. 19), I adapt examples from Garcia (2015b, p. 641). While the arguments put forth in these paragraphs are attributed to Garcia, references to Garcia's (2015b, p. 641) original examples should be included.

The first sentence of the penultimate paragraph on page 17 should contain a reference to Garcia (2015a, p. 152).

In the third and fourth paragraph of Section 5.4 (p. 20), I reproduce arguments from Garcia (2015b, p. 648) and Garcia (2015b, p. 646), respectively. The provided references to these passages should be without "cf."

\section{References}

Armstrong, D. (1997). A world of states of affairs. Cambridge: Cambridge University Press.

Campbell, K. (1990). Abstract particulars. Oxford: B. Blackwell.

Funkhouser, E. (2006). The determinable-determinate relation. Noûs, 40(3), 548-569.

Garcia, R. K. (2015a). Is trope theory a divided house? In M. Loux \& G. Galluzzo (Eds.), The problem of universals in contemporary philosophy (pp. 133-155). Cambridge: Cambridge University Press.

Garcia, R. K. (2015b). Two ways to particularize a property. Journal of the American Philosophical Association, 1(4), 635-652.

Gillet, C., \& Rives, B. (2005). The non-existence of determinables: Or, a world of absolute determinates as default hypothesis. Noûs, 39(3), 483-504.

Hommen, D. (2017). Ontological commitments of frame-based knowledge representations. Synthese. https: //doi.org/10.1007/s11229-017-1649-8. 